\title{
COMPLETELY CO-BOUNDED SCHUR MULTIPLIERS
}

\author{
GILLES PISIER
}

Abstract. A linear map $u: E \rightarrow F$ between operator spaces is called completely co-bounded if it is completely bounded as a map from $E$ to the opposite of $F$. We give several simple results about completely co-bounded Schur multipliers on $B\left(\ell_{2}\right)$ and the Schatten class $S_{p}$. We also consider Herz-Schur multipliers on groups.

Mathematics subject classification (2010): 47L07,47L25.

Keywords and phrases: Completely bounded map; operator space; transposition; multiplier.

\section{REFERENCES}

[1] M. BOżEJKO AND G. FendLER, Herz-Schur multipliers and completely bounded multipliers of the Fourier algebra of a locally compact group, Boll. Unione Mat. Ital. (6) 3-A (1984), 297-302.

[2] E. G. EFfros and Z. J. RuAn, Operator Spaces, The Clarendon Press, Oxford University Press, New York, 2000, xvi+363 pp.

[3] U. HaAgerup AND M. Musat, The Effros-Ruan conjecture for bilinear forms on $C^{*}$-algebras, Invent. Math. 174 (2008), 139-163.

[4] W. MAJEWSKI AND M. MARCINIAK, $k$-decomposability of positive maps, Quantum probability and infinite dimensional analysis, 362-374, QP-PQ: Quantum Probab. White Noise Anal., 18, World Sci. Publ., Hackensack, NJ, 2005.

[5] M. MARCINIAK, On extremal positive maps acting between type I factors, arXiv:0812.2311.

[6] G. PISIER, Non-commutative vector valued $L_{p}$-spaces and completely $p$-summing maps, Astérisque 247 (1998), vi+131 pp.

[7] G. PISIER, Similarity problems and completely bounded maps, Springer Lecture Notes 1618, Second Expanded Edition. (Incl. the solution to "the Halmos Problem") (2001), 1-198.

[8] G. PISIER, Introduction to operator space theory, London Mathematical Society Lecture Note Series, 294, Cambridge University Press, Cambridge, 2003, viii+478 pp.

[9] G. PISIER AND D. ShLYAKHTENKo, Grothendieck's theorem for operator spaces, Invent. Math. 150, 1 (2002), 185-217.

[10] Q. XU, Operator-space Grothendieck inequalities for noncommutative $L_{p}$-spaces, Duke Math. J. 131 (2006), 525-574. 